\title{
Changes of Meanings in Multiplication across Different Contexts: The Case of Amy and Beth
}

\author{
Kin Eng Chin ${ }^{1 *}$, Fui Fong Jiew ${ }^{2}$ \\ ${ }^{1}$ Flinders University, Adelaide, AUSTRALIA \\ 2 Universiti Malaysia Sabah, Sabah, MALAYSIA
}

Received 29 August 2018 - Revised 4 November 2018 • Accepted 7 February 2019

\begin{abstract}
This article focuses on how two mathematics teachers (Amy and Beth - pseudonyms) cope with the changes of meanings in multiplication due to the changes of contexts. It highlights the qualitative similarities and differences between these two teachers in the sense-making process of multiplication. A potentially useful framework of supportive and problematic conceptions suggested by Chin (2013) and Chin (2014) is employed in this study. Interviews are performed with Amy and Beth in order to collect the necessary data. Findings reveal that both teachers try to make sense of multiplication by building on the conception of repeated addition across different number systems. When multiplication is operated with negative numbers then problematic aspects emerge within the conception of repeated addition. It is observed that both teachers didn't build on the meaning of repeated addition in the multiplication of fractions.
\end{abstract}

Keywords: changes of meanings, multiplication, problematic conception, sensemaking, supportive conception

\section{INTRODUCTION}

Nicholas, Poladin, Mack, and Wilson (2015) stated that the success of mathematics at university level depends on the level of mathematics studied at secondary school. This means that mathematics serve as a critically vital subject for students to undertake in secondary school. However, there was a decreasing trend in mathematics enrolments in elementary, intermediate and advance levels of mathematics in particular in South Australia and only a small increase in enrolments in Advanced level mathematics in New South Wales (Forgasz, 2006). Likewise, Wilson and Mack (2014) also noticed the decline in number of students enrolling in higher-level and intermediate secondary school mathematics in Australia. As an effort to uplift the rate of enrolment and to boost the number of students in studying mathematics, the New South Wales Government intended to recruit 100 new specialist primary school mathematics teachers (The Sydney Morning Herald, 2018). This is obviously a great idea if trained teachers can make sense mathematical concepts so that they can guide students to truly understand the meanings of concepts without rote learning. In addition, a focus needs to be given to the basic arithmetic operations of mathematics because they are the elementary part of the number theory. Among the four basic arithmetic operations, multiplication is viewed with different meanings when context changes. Thus, teachers' understanding on the meanings of multiplication deserves a study.

The understanding of multiplication often related to a total amount when the number of groups and the number in each group are known. More formally, the number of groups indicates the multiplier and the number in each group refers to the multiplicand, giving the total amount as the product (Simon \& Blume, 1994). For example, there are three bags of marbles and the number of marbles in each bag is two. In this case, the multiplier is three whereas the multiplicand is two. The product which represents the total amount of marbles is six. Based on Siemon et al. (2015, p.278), we may interpret multiplication as one-to-many correspondence. Take for instance, there are three bags of wool on each sheep, five sheep are carrying the wools. The idea in this case is, three times as many bags of wool as sheep. However, many children do not know what multiplication is (O'Brien \& Casey, 1983), they cannot tell when this operation can be used. Hence, sense making is essential in furnishing them fundamental ideas as well

(C) 2019 by the authors; licensee Modestum Ltd., UK. This article is an open access article distributed under the terms and conditions of the Creative Commons Attribution License (http://creativecommons.org/licenses/by/4.0/). \kineng.chin@flinders.edu.au (*Correspondence) $邓$ jiewfuifong@gmail.com 


\section{Contribution of this paper to the literature}

- This study fills in a research gap that focuses on how mathematics teachers cope with the changes of meanings in multiplication due to the changes of contexts.

- This paper introduces and demonstrates a potentially useful framework that can be used to understand the sense making process of humans and this framework is known as the supportive and problematic conceptions in making sense of mathematics.

- Findings indicate that the way that a mathematical formula was written could induce certain interpretations and this lead to the formulation of the notion of problematic convention in mathematics.

as to develop conceptual structures in learning mathematics. In this regard, teacher serves an important part to help students to see and reason the links between the multiplier, the multiplicand and the product. With the proper guidance from teachers, students can develop the sense making through reasoning.

This article aims to explore how two primary mathematics teachers cope with the changes of meanings in the process of making sense of multiplication. It presents a divergence of personal conceptions of multiplication across different contexts between two primary school mathematics teachers. The data revealed that their conceptions were heavily influenced by the historical meaning of multiplication (repeated addition) in making sense of this concept. On top of that, a snapshot on how the participants struggled to build their own conceptions of multiplication was highlighted. Given the complication of multiplication, it will be fruitful to explore how mathematics teachers cope with the changes of meanings due to the changes of contexts.

\section{MULTIPLICATION}

Approaches for students to learn multiplication have been widely modelled, scaffolded and discussed. As a result there are many research studies on multiplication with different foci such as array representation (Barmby, Harries, Higgins, \& Suggate, 2009; Young-Loveridge, 2005), classroom-based studies and rectangular areas which done by Izsák (2004), understanding among prospective teachers (Lo, Grant \& Flowers, 2008; Thanheiser, 2010; Whitacre \& Nickerson, 2016). An array is a rectangular arrangement of discrete objects in rows and columns. It allows students to observe all objects of a multiplicative situation at once at the same time also allows students to create a visual depiction of what the multiplicative sentence represents (Young-Loveridge, 2005). This 'typical' picture enables students to see that the multiplication of whole numbers is independent of the order (Tall, 2013). The idea of array also indicates a shift in fundamental meaning (repeated addition) to a multiplicative process (Siemon et al., 2015). Izsák (2004) emphasised on two-digit multiplication and rectangular area in classroom practices. In this study, classroom practices and individual students were compared using features of rectangular area representations in order to complete the same problem solving goals. He found that multiple representations were needed in teaching and learning multiplication. On the other hand, there are also studies which showed that students operate multiplication solely based on procedural skills of multiplication without understanding (Simon \& Blume, 1994; Sudarshan \& Aye, 2008). This is coherent with Seah (2004) who argued that most pupils were restricted to procedural skills and demonstrated very limited understanding of multiplication. This situation is likely due to weak mathematical knowledge among mathematics teachers as they have gone through a school time that generally does not teach them to make sense of mathematics instead treat mathematics as a body of memorised knowledge (Lampert, 1986a). Knowing when to multiply and determining an appropriate approach to solve a mathematical task requires deep understanding of the operation. However, Smith and Smith (2006) found that the curriculum and instruction that emphasize on the memorization of multiplication facts have produced students with less understanding of the basic concepts of multiplication. They also claimed that most of the teaching methods had narrowed students' focus and given the wrong impression about the concept of multiplication. Likewise, Larsson, Pettersson and Andrews (2017) stated that the way teachers introduce multiplication to students as repeated addition is a problematic instruction, particularly when multiplication is extended to multi-digits and decimals. Whitacre and Nickerson (2016) also pointed out that prospective teachers need to be able to make sense of mathematics and use their prior knowledge as a resource in learning. Jiew and Chin (in press) explored further by investigating how prior knowledge can support or impede the sense making of multiplication in new contexts. In this case, contexts refer to number systems. Due to the changes of meanings of the multiplication symbol across different contexts, the respondent faced difficulties in making sense of this concept (Jiew \& Chin, in press). Their study suggested a need to develop a new course in teacher education so as to highlight the importance of supportive and problematic conceptions in students' learning. All these studies indicate a necessity to explore how mathematics teachers make sense of multiplication based on their personal conceptions that are developed through prior experience or existing knowledge.

Learning multiplication is an essential part of primary school mathematics. Clark and Kamii (1996) demonstrated that multiplication was developed as a transition from additive to a multiplicative way of thinking. 
Multiplicative thinking is efficient for the counting of large collections (Siemon, Breed, \& Virgona, 2005). As an illustration, we can write $2 \times 3$ as $3+3$ and interpret it as the total number of things in the two groups, each containing three things. Obviously, this kind of interpretation is derived from the operation of addition. Supporting evidence came from Fischbein, Deri, Nello and Marino (1985) who claimed that the concept of multiplication is intuitively attached to a repeated addition model but the multiplier must be a whole number. Greer (1992), Izsák (2005) and Kouba (1989) also found that students tended to solve multiplication problems based on equal groups of repeated addition. However, some researches (Devlin, 2007; Kaput, 1985; Larsson et al., 2017) disagreed to reason multiplication solely based on repeated addition. Although equal groups is the starting point for multiplication, Siemon et al. (2015) stated that this idea is only suitable for small positive integers, not helpful in fractions and decimals and does not apply to negative numbers. Consequently, the interpretation of multiplication as repeated addition has been extended from the notion of "times" to "part of a part' in the multiplication of fractions (Mack, 2001; Webel \& DeLeeuw, 2015) or alternatively the notion 'of'. All these open up a question about what is the meaning of multiplication when it involves negative numbers. The meaning of multiplication changes based on contexts. Take for instance, how can we interpret $-4 \times-5$ ? The total number of things in the -4 group, each containing -5 thing? This invites another question on how mathematics teachers cope with the changes of meaning in multiplication across different contexts, in particular from the contexts of natural numbers to integers and to fractions.

\section{THE FRAMEWORK OF SUPPORTIVE AND PROBLEMATIC CONCEPTIONS}

According to NCTM (2009), "sense making may be considered as developing understanding of a situation, context, or concept by connecting it with existing knowledge or previous experience" (p.4). This sparks a deeper question of how existing knowledge or prior experience may affect humans' sense making of a mathematical concept. The work of Chin and Tall (2012), Chin (2013) and Chin (2014) have shown that humans' conceptions on mathematical concepts that shape from existing knowledge and prior experience have affected the way an individual makes sense of a situation. They proposed the framework of supportive and problematic conceptions in making sense of mathematics in order to highlight how humans' conceptions that developed from previous contexts that may support or impede the sense making of a new context. This framework was built upon the notion of met-before as proposed by Lima and Tall (2008). A met-before refers to a trace it leaves from previous experience that affects the current thinking of a learner and it highlights the importance of prior experience in shaping mathematical conception. It should be noted that different kinds of met-befores may be incorporated into conceptions (Chin, 2013). What is a conception? Based on Sfard (1991), a conception is described as "the whole cluster of internal representations and associations evoked by the concept - the concept's counterpart in the internal, subjective universe of human knowing" (vol 22, p.3). Tall and Vinner (1981) used the term concept image to indicate the total cognitive structure associated with a concept that might include mental images, representations, processes and properties. Additionally, they also proposed the term concept definition to represent a form of words used to specify a concept. While mathematics community may agree on a definition for a particular concept with associated representations however in reality the way a learner makes sense of a particular concept does not depend solely on the given concept definition and representations.

In general, a conception refers to the interpretation that an individual has for a particular concept. When different kinds of personal met-befores blend together then an individual may develop its own conceptions for a concept. An individual may use different conceptions in responding to different situations. Different conceptions may have aspects that are supportive and aspects that are problematic. The framework of supportive and problematic conceptions may be regarded as a potentially useful framework to understand how humans make sense of mathematics because it offers readers a new insight on how humans reconstruct their knowledge schemas. Based on Chin (2013), supportive conceptions refer to conceptions that work in an old context and continue to work in a new context. Take for instance, the conception of multiplying two negative numbers together will yield a positive number can be regarded as a supportive conception in a new context such as fractions. This conception might have arisen from the context of integers. On the other hand, problematic conceptions refer to conceptions that work in an old context but do not work in a new context. As an illustration, the conception of multiplication makes bigger is true for the context of integers however this conception may be considered as a problematic conception in a new context such as fractions because multiplication of fractions makes smaller. This is not the whole story. A supportive conception may contain problematic aspect(s). The work of Chin (2014) has shown that a student teacher who possessed a supportive conception of sine curve that can be used for any values of angle did have a problematic aspect. In this respect, the problematic aspect was the student teacher didn't know how to derive this curve when the angle involved was greater than $90^{\circ}$. He could only make sense of the sine curve when the angle was between $0^{\circ}$ and $90^{\circ}$. On the contrary, a problematic conception may contain supportive aspect(s). As an illustration, the conception of treating $i$ (the imaginary unit of a complex number) as a pronumeral may be regarded as a problematic conception by some learners because the meaning of $i$ is $\sqrt{-1}$ whereas the meaning for a 


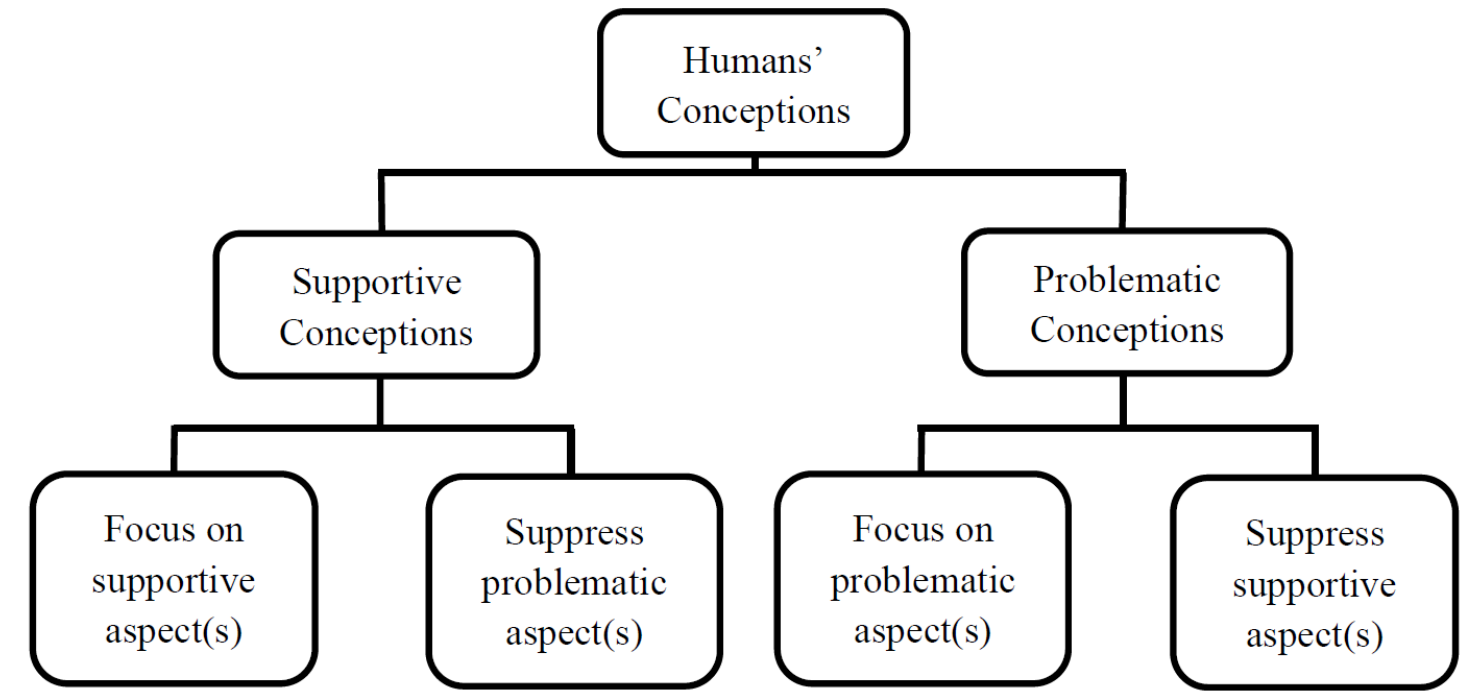

Figure 1. Supportive and Problematic Conceptions

pronumeral is a real variable. However, there is a supportive aspect in this problematic conception that is the way we operate them in multiplication. For instance, $(1+2 i) \times(2+i)=2+i+4 i+2 i^{2}$ and this is similar with $(1+2 a) \times(2+a)=2+a+4 a+2 a^{2}$, where $a$ is a pronumeral. This shows that learners can treat $i$ as if it is a pronumeral in performing the multiplication. The framework of supportive and problematic conceptions is illustrated in Figure 1.

The subjective nature of personal conceptions contributes partly to the performance divergence among learners. Imagine in a mathematics classroom, every student follows the same lesson and read the same material as requested by the teacher but at the end of the lesson we can see achievement discrepancies among the students. One sensible explanation for this scenario is due to the subjective nature of personal conceptions on mathematical concepts that leads to different interpretations and understanding. The categorization of supportive conceptions and problematic conceptions are purely personal depending on how an individual interprets a particular concept at a particular time. On top of that, this also relates to what aspect that an individual might focus at a particular time. The work of Chin and Jiew (in press) showed that two undergraduate mathematics students had different responses for an inequality statement shown to them. Student M2 felt that $2+3 i<4+3 i$ was correct and reasoned that $3 i$ can be canceled out. This showed that this individual was conceiving $3 i$ as if it was a real pronumeral. Student M1 used his mental image of complex numbers and reasoned that complex numbers cannot be fully represented on a straight line thus he responded that $2+3 i<4+3 i$ was not correct. Obviously, both of them used different aspects of their conceptions on complex numbers to reason this situation. M2 focused on the operational aspect whereas M1 the other student focused on the visual representation aspect. M1 considered the experience of operating real pronumeral was supportive. On contrary, M2 realised that complex numbers were not ordered by noticing the differences with real numbers graphically. This means that he was aware of his problematic conception at this particular instance. In this case, we can see that the categorization of supportive or problematic conceptions was purely subjective. When an individual focuses on the supportive aspect(s) of a conception and suppresses the problematic aspect(s) then this conception may be regarded as a supportive conception. On the other hand, when an individual focuses on the problematic aspect(s) and suppresses the supportive aspect(s) then this conception may be regarded as a problematic conception. Bear in mind that sometimes humans may not be aware of the supportive aspect(s) or the problematic aspect(s) that they wish to suppress.

\section{METHODOLOGY}

This paper aims to answer four research questions as outlined below:

1) What are the problematic conceptions in making sense of multiplication?

2) How do the teachers deal with their supportive conceptions or problematic conceptions?

3) To what extent are the teachers aware of the changes of meaning?

4) Does the teachers' different educational background make a difference in making sense of multiplication?

A case study research design was employed because it gave an opportunity to study how school teachers make sense of multiplication in depth within a limited time scale. This study took place in two different schools in Malaysia by using the purposive sampling method. Interviews were conducted after the school time to avoid 
instructional disturbance. In this paper, we report the data about multiplication that was collected by interviewing two mathematics teachers (Amy and Beth - pseudonyms). Both of them taught at two different primary schools. They were chosen purposively based on two criteria. The first criterion was their education background. In Malaysia, all the undergraduate degrees of public universities are classified as first-class honours, upper secondclass honours, lower second-class honours and third-class honours. A first-class honours degree is the highest honours classification and indicates high academic achievement then follow by upper second-class honours. Thirdclass honours is the lowest classification. The class of an honours degree is based on a weighted average mark of the assessed work a candidate has completed. The maximum cumulative grade point average is 4.00 . In this respect, a first-class honours degree is awarded to candidates with a cumulative grade point average in between 3.67 and 4.00. An upper second-class honours is awarded to candidates with a cumulative grade point average in between 3.00 and 3.66. Amy possessed a first-class honours bachelor degree in mathematics education and a master degree in statistics. On the other hand, Beth had an upper second-class honours bachelor degree in mathematics education. Superficially, we can see Amy has a better and higher education background in comparison with Beth. The second criterion was based on their years of teaching experience. Both Amy and Beth had 5 years of school teaching experience. At the onset of the study, we sent invitations to Amy and Beth. Both of them agreed to participate in our study on a voluntary basis. Then we arranged a specific time with each of them for an interview.

The interview protocol was set in a way to elicit participants' conceptions on multiplication in different contexts. This is done by asking the participants to explain their sense-making for the given mathematical expressions that involved the multiplication of natural numbers, integers and fractions. The participants were also required to give an example of real life problem for every instance. The interview was conducted for an hour. The collected data was analysed based on the framework of supportive and problematic conceptions as discussed in the previous section.

We employed the quasi judicial method of analysis in analyzing the collected data in order to be as objective as possible. In this respect, we were not only searching for evidence that will support the framework but also those evidence that will contrary to the proposed framework. In order to reduce bias in interpreting the data, we showed our data analysis to two other experienced mathematics educator researchers to seek for other alternative interpretations that might contrary to the proposed framework. The quasi judicial method of analysis was proposed by Bromley $(1986,1990)$ and this method also focuses on looking for evidence so as to eliminate as many of the suggested explanations as possible. Based on Bromley (1986), a psychological case study is sufficient to explain how and why an individual behaves in a particular way in a context provided that it "contains enough empirical evidence, marshaled by a sufficiently cogent and comprehensive argument, to conceive competent investigators that they understand something that previously puzzled them" (p.37). The interpretation of data maybe regarded valid if it informs a coherent whole.

\section{RESULTS}

\section{Amy and Beth's Initial Conceptions of Multiplication}

We first explored how Amy and Beth interpreted the meaning of multiplication in the context of natural numbers. Hence, we asked them to explain the meaning for $2 \times 3$. This allowed us to explore the participants' initial conceptions of multiplication. In the excerpts, we use " $R$ " to represent the researcher, " $A$ " for Amy and " $B$ " for Beth.

Excerpt 1a: Amy's interpretation of $2 \times 3$

R: What do you understand about $2 \times 3$ ?

A: Two groups of three items, equal to six items in total.

$\mathrm{R}$ : What is multiplication in this case?

A: Repeated addition.

Amy activated her current knowledge of multiplication for the context of natural numbers. She interpreted $2 \times 3$ as two groups of three and she further explained that multiplication was repeated addition in this case. Based on her response, we can infer that she had a conception that $x$ times $y$ meant $x$ of quantity $y$.

Excerpt 1b: Beth's interpretation of $2 \times 3$

R: What do you understand about $2 \times 3$ ?

B: Three items times two.

R: What is multiplication in this case?

B: Repetition. Repeat three two times because two is the multiplicand and three is the multiplier. Multiplicand is the number of time and multiplier is the quantity. 


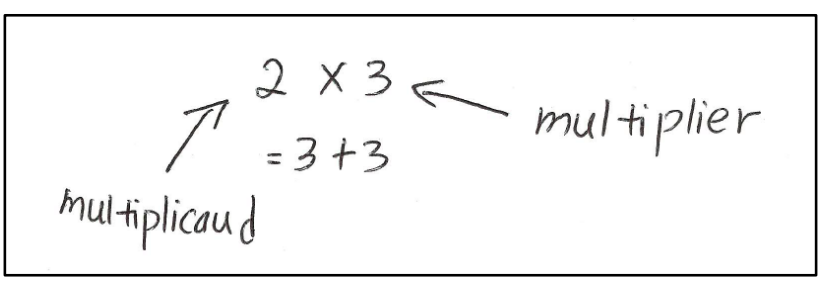

Figure 2. Beth's interpretation of $2 \times 3$

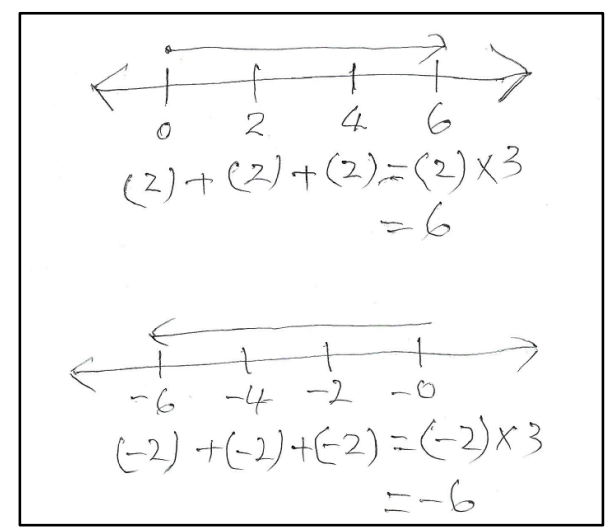

Figure 3. Amy's interpretation of $-2 \times 3$

Beth interpreted $2 \times 3$ as $3+3$ (see Figure 2) and she was referring multiplication as repeated addition. Based on her response, we can generalize that she was conceiving $x$ times $y$ as $x$ of quantity $y$.

\section{Evolution of the Meaning for Multiplication}

\section{Extending to negative numbers}

We asked further questions to explore how Amy and Beth built from their initial interpretation of multiplication. In this respect, we asked them to respond for the expression of $-2 \times 3$.

Excerpt 2a: Amy's interpretation of $-2 \times 3$

$\mathrm{R}$ : What is $-2 \times 3$ ? What is the meaning of multiplication in this case?

A: Repeated addition. We can move in positive or negative direction on a number line.

R: So what is $-2 \times 3$ ?

A: Moving negative direction of two for three times, still repeated addition.

According to Amy's responses for $2 \times 3$, we can infer that she had a general conception of $x$ times $y$ as $x$ of quantity $y$. Building from this general conception, she interchanged the positions of $x$ and $y$ of the given expression to become $y$ of quantity $x$. Thus $-2 \times 3$ is conceived as $3 \times-2$. Hence, she interpreted $3 \times-2$ as 3 of quantity -2 . She elaborated this based on a number line to indicate -2 as negative direction (see Figure 3 ). If she did not modify the given expression then she will have to interpret $-2 \times 3$ as -2 of quantity 3 which will be problematic for her to explain using the notion of repeated addition. Therefore she removed this problematic aspect by interchanging the positions of the given numbers. She used the commutative law of multiplication to remove this problematic aspect in order to build a consistent meaning for multiplication.

In this case, the problematic aspect arose due to the first number in the multiplication was not a counting number. For Amy, repeated addition may be conceived as a supportive conception with a problematic aspect for $-2 \times 3$ because she will not be able to explain it by using the notion of repeated addition without modifying the given expression. She managed to interpret $-2 \times 3$ as repeated addition by removing the problematic aspect through interchanging the position of $x$ and $y$ of her general conception. However, when we reflect deeply, $-2 \times 3$ is equivalent to $-(3)-(3)$ which means taking away 3 for twice. Multiplication in this case is repeated subtraction. According to Kilham (2011), "The number of times a multiplicand is either added or subtracted could be mapped onto a signed number, so that a positive multiplier means an iterated addition and a negative multiplier means an iterated subtraction" (p.103). In this respect, Kilham (2011) referred $p$ as a multiplier for the expression $p \times q$. 


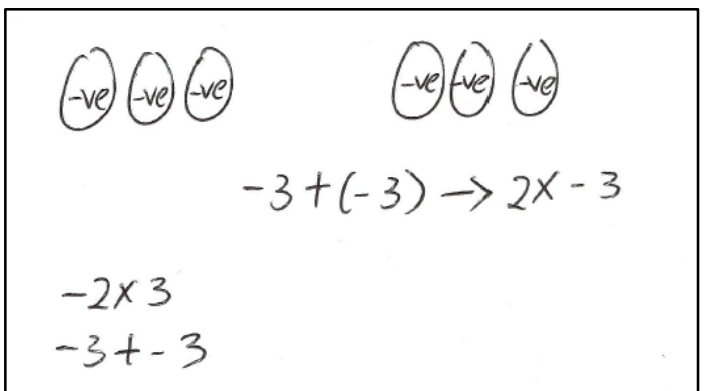

Figure 4. Beth's interpretation of $-2 \times 3$

Excerpt 2b: Beth's interpretation of $-2 \times 3$

$\mathrm{R}$ : What is the meaning of multiplication for $-2 \times 3$ ?

B: Repetition. Repeat three negative two times.

R: What do you mean by negative two times?

B: Let me show you (see Figure 4)...... Erm... seems like not correct.

R: Why?

B: I can't show by using the diagram. Since $2 \times 3$ is $3+3 \ldots-2 \times 3$ can be written as $\ldots 3+3 \ldots$ Add a negative in front of the three! It's -3 plus -3 !

$\mathrm{R}$ : Why did you add negative in front of the three?

B: So that I can get the answer -6 . Well, it is still repetition.

$\mathrm{R}$ : What is -3 plus -3 in this case?

B: Owing three apples first day, owing another three apples second day, so total owing six apples.

R: What about $2 \times-3$ ?

B: Erm...... actually $2 \times-3$ and $-2 \times 3$ are the same. You still get negative six at the end, no need bother which one comes first.

R: But just now you did mention that multiplicand indicates the number of times while multiplier indicates the quantity?

B: Yes it is good if we can tell in that way but if there is a negative multiplicand, we can just give the negative sign to multiplier.

In an earlier instance, she had the conception that $x$ times $y$ meant $x$ of quantity $y$. Building from this conception thus she explained that $-2 \times 3$ was repeating 3 for negative two times but immediately she sensed the problematic aspect as she could not repeat something for negative two times. Then, she tried to conceive $-2 \times 3$ as $(-3)+$ $(-3)$ (see Figure 4). However, according to her responses about $(-3)+(-3)$, she interpreted the first $(-3)$ as owing three apples on the first day and the second $(-3)$ as owing another three apples for the second day. This interpretation was incorrect because owing three apples first day and owing another three apples second day should be represented symbolically as $2 \times-3$. Despite that, she still conceived $-2 \times 3$ and $2 \times-3$ are the same due to the same product. She ignored the difference in meaning between $-2 \times 3$ and $2 \times-3$ and she was focusing on the final answer of the two expressions.

Similar to Amy, Beth was trying to remove the perceived problematic aspect by getting the first number to be a counting number for the given expression. Hence, she transferred the negative sign to 3 so that she can explain it by using the notion of repeated addition. In this case, repeated addition is conceived as a supportive conception with a problematic aspect for $-2 \times 3$ because she could not explain it by using the notion of repeated addition without transferring the negative sign to 3 . After transferring the negative sign to 3 to remove the problematic aspect then she eventually can interpret it as repeated addition. However, if we reflect deeply, $-2 \times 3$ is equivalent to $-(3)-(3)$ which means taking away 3 for twice thus multiplication in this case can be interpreted as repeated subtraction.

\section{Multiplication of two negative numbers}

We probed further by asking Amy and Beth to interpret the meaning of $-2 \times-3$ to see how they made sense of this expression based on their earlier general conception. For the previous expression $-2 \times 3$, Amy interchanged the positions of -2 and 3 so that she could interpret it as repeated addition. On the other hand, Beth was forcing 


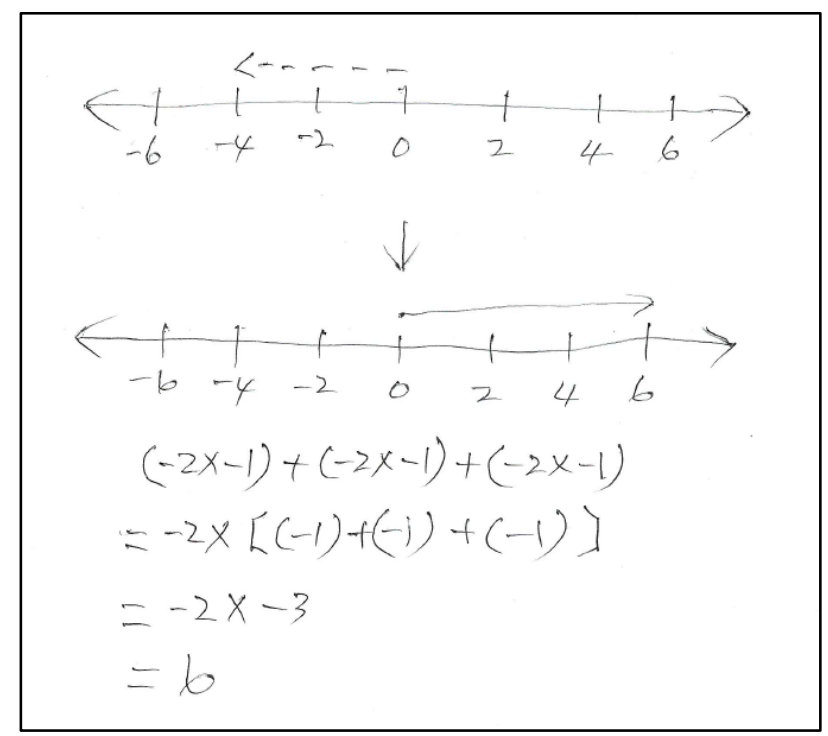

Figure 5. Amy's interpretation of $-2 \times-3$

the meaning of repeated addition to the expression $-2 \times 3$ by focusing on the answer of that expression, ignoring the difference in meaning between $-2 \times 3$ and $2 \times-3$.

Excerpt 3a: Amy's interpretation of $-2 \times-3$

$\mathrm{R}$ : What is $-2 \times-3$ ?

A: Six.

R: Why it is six?

A: $2 \times 3$ is a positive multiplication. You can do the same way for repeated addition. For example, if two means saving 2 dollars, then $2 \times 3$ means starting from zero you save 2 dollars for 3 times, so you get 6 dollars. For $-2 \times 3$ which is also a positive multiplication, you can do the same way for repeated addition too. If -2 means you lack of 2 dollars, then $-2 \times 3$ means, starting from zero, you lack of 2 dollars for 3 times, so you lack of 6 dollars.

$\mathrm{R}$ : So what is the meaning of multiplication in this case?

A: Still repeated addition but opposite way.

R: What do you mean by the opposite way of repeated addition?

A: Moving opposite side in number line, opposite meaning, for example lacking becomes earning.

Amy initially defined -2 as lacking of 2 dollars then she explained $-2 \times 3$ as lacking of 2 dollars for three times. Using a number line, she interpreted it as moving to the left side of zero (see Figure 5). However, she further explained that $-2 \times-3$ is in opposite direction due to the existence of negative sign in front of 3 . Instead of moving left, now moving to the right side of zero on a number line. Hence, instead of lacking 2 dollars for three times, now becomes earning 2 dollars for three times. Building from her conception for $-2 \times 3$ that means moving to the left side of zero, she embodied the operation of $-2 \times-3$ by using the number line and interpreted this expression as moving to the right side of zero and obtained the final answer as 6 . Then, she divided the whole movement to 6 as three steps on the number line so that she can conceive $-2 \times-3$ as repeated adding the steps for three times. After that, she expressed these three steps on a number line by using symbolism thus she wrote $(-2 \times-1)+(-2 \times-1)+$ $(-2 \times-1)$. She used the distributive property of multiplication to get $-2 \times[(-1)+(-1)+(-1)]$.

In the case of $-2 \times-3$, both the multiplicand and multiplier are not counting numbers. For Amy, repeated addition was a supportive conception with problematic aspect. Amy had to conceive $-2 \times-3$ as moving in an opposite direction of $-2 \times 3$ in order for her to build a coherent understanding about multiplication as repeated addition. However her interpretation was incorrect because moving from 0 to 6 with three steps on a number line should be expressed as $3 \times 2$ but not as $-2 \times-3$. At this particular instance, $-2 \times-3$ may be interpreted as an individual who takes away two times of -3 and this situation can be embodied as moving from 0 to -6 and then flipping from -6 to 6 on a number line (Tall, 2013).

Excerpt 3b: Beth's interpretation of $-2 \times-3$

$\mathrm{R}$ : What is the meaning of multiplication for $-2 \times-3$ ?

B: (Writing)...Initially we have $2 \times 3$, which is $3+3$. Then we have $-2 \times 3$, add negative in front become -3 plus -3 . Now $-2 \times-3$, add negative again become $-(-3)+[-(-3)]$. 


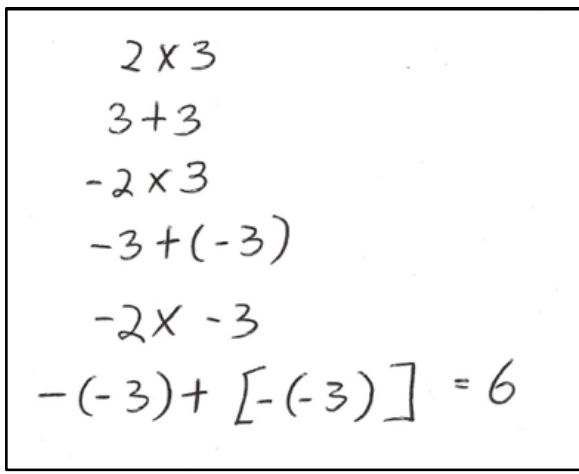

Figure 6. Beth's interpretation of $-2 \times-3$

At first, Beth interpreted $-2 \times 3$ as $(-3)+(-3)$ then for $-2 \times-3$, she added another minus sign to both -3 to become $-(-3)+[-(-3)]$. At this particular instance, Beth perceived repeated addition as a supportive conception with a problematic aspect for the expression $-2 \times-3$. The problematic aspect was caused by -2 . Based on Figure 6, her interpretation of $-2 \times-3$ can be written as $-A+(-A)$ symbolically with $A=-3$ because $-2 \times-3=$ $[-(-3)]+[-(-3)]$. Just like the previous case, it was most likely that she transferred the negative sign to $A$ and subsequently arrived at a conclusion of $-(-3)+[-(-3)]$. This chronology can be illustrated symbolically as below:

$$
\begin{gathered}
-2 \times-3=-2 \times A(\text { Let } A=-3) \\
=2 \times(-A) \\
=(-A)+(-A)
\end{gathered}
$$

Indeed her interpretation was incorrect because $-2 \times-3$ may be conceived as $-(-3)-(-3)$ which means taking away $(-3)$ for twice. In this case, it was a repeated subtraction. Building from her response in the previous question, she might be conceiving $(-A)$ as an object.

\section{Extending to fractions}

We explored further the conceptions of Amy and Beth on the multiplication of fractions. The first expression was about making sense of $\frac{1}{2} \times 2$.

Excerpt 4a: Amy's interpretation of $\frac{1}{2} \times 2$

$\mathrm{R}:$ What is $\frac{1}{2} \times 2$ ?

A: Take half of two, get one.

$\mathrm{R}$ : What is the meaning of multiplication in this case?

A: We have two sets of halves, get one whole set.

$\mathrm{R}$ : Is multiplication still having the meaning of repeated addition in this case?

A: Yes, half plus half is one.

R: What if $2 \times \frac{1}{2}$ ?

A: Still two half to get one.

It was problematic for Amy to explain $\frac{1}{2} \times 2$ as repeated addition because $\frac{1}{2}$ is not a counting number. She said "Take half of two, get one" and this indicated her subconscious interpretation of multiplication as "of". She again used her modified general conception of multiplication to explain $\frac{1}{2} \times 2$ as adding half of two. She was trying to make sense of multiplication based on her supportive conception that was repeated addition. Again, she removed the problematic aspect by using the commutative law of multiplication which led her to interpret $\frac{1}{2} \times 2$ as $2 \times \frac{1}{2}$. In this case, she interpreted it as two sets of halves. In fact, the meaning of multiplication in this particular instance has changed from repeated addition to the notion 'of'. $\frac{1}{2} \times 2$ is actually half of two. Amy did mention half of two (see Excerpt 4a) but she was not aware of the change of meanings for multiplication at this particular instance. Multiplication may be interpreted as "of" in this case. 


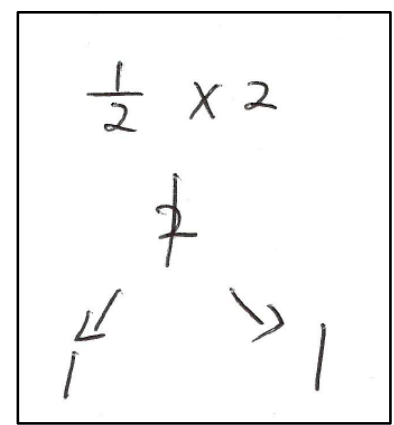

Figure 7. Beth's interpretation of $\frac{1}{2} \times 2$

\section{Excerpt 4b: Beth's interpretation of $\frac{1}{2} \times 2$}

$\mathrm{R}:$ What is $\frac{1}{2} \times 2$ ?

B: Half times of two so is one... Erm... Originally we have two then we repeat half means we write half of two instead of the full two so we have one!

$\mathrm{R}$ : What is the meaning of multiplication here?

B: Simplify.

R: What are we simplifying?

B: Erm...divide! Not simplify. Two divided by two people so it is one. So the meaning is divide.

R: How can multiply become divide?

B: Division is reverse of multiplication. So when we multiply a fraction, it becomes reverse of multiplication, so it becomes divide.

Beth was confused with the meaning of multiplication in this particular instance. She was focussing on the final answer of $\frac{1}{2} \times 2$ that was 1 and said "repeat half means we write half of two instead of the full two so we have one!" She did mention "half of two" but she was not aware of the meaning for multiplication as "of". It was problematic for Beth to explain $\frac{1}{2} \times 2$ as repeated addition because $\frac{1}{2}$ is not a counting number. She interpreted the meaning of multiplication in this case as divide. In order to get the product for $\frac{1}{2} \times 2$, she divided 2 into two equal parts (see Figure 7). Hence, she interpreted the meaning of multiplication in this case as division by focusing on the performed operation in symbolism (i.e. $\frac{1}{2} \times 2=\frac{2}{2}$ ) but not the meaning of the multiplication symbol itself. In fact, the meaning of multiplication in this particular instance has changed from repeated addition to the notion 'of'. In this respect, $\frac{1}{2} \times 2$ is actually half of two.

\section{Multiplication of two fractions}

We asked the participants to make sense the expression $\frac{1}{2} \times \frac{1}{3}$ in order to explore how they cope with the change of mathematical meanings.

Excerpt 5a: Amy's interpretation of $\frac{1}{2} \times \frac{1}{3}$

$\mathrm{R}$ : What do you understand about $\frac{1}{2} \times \frac{1}{3}$ ?

A: Take $\frac{1}{3}$ of it. Fraction a $\frac{1}{3}$ cake into half.

R: Can you explain further?

A: I have a cake which is cut into three parts, take one out of it. Then cut it into half again to get $\frac{1}{6}$.

R: What about $\frac{1}{3} \times \frac{1}{2}$ ?

A: It's the same. We eventually get $\frac{1}{6}$.

R: So what is the meaning of multiplication in the case of $\frac{1}{2} \times \frac{1}{3}$ ?

A: Have each set as one, then take a fraction or multiple of it. 


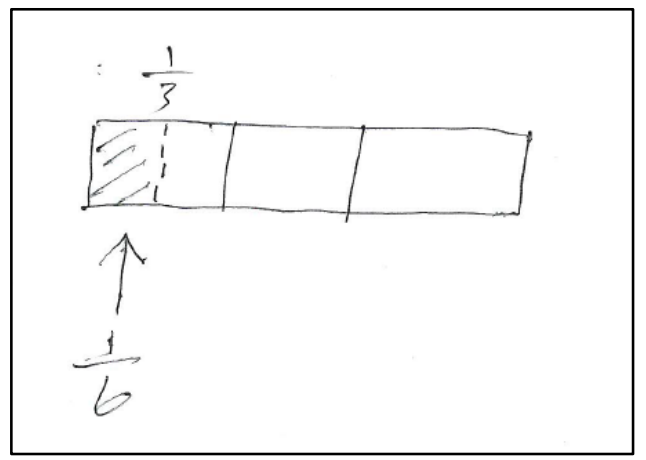

Figure 8. Amy's interpretation of $\frac{1}{2} \times \frac{1}{3}$

\section{R: Still repeated addition?}

A: ...... I can't see addition here. Just take out a fraction or multiple of it.

In the multiplication of two fractions, take for example $x$ times $y$ where $x$ and $y$ are fractions, we can generalise this concept to mean $x$ of $y$. Amy interpreted $\frac{1}{2} \times \frac{1}{3}$ as half of one third. She used the commutative law of multiplication to free her from giving meaning to $\frac{1}{3} \times \frac{1}{2}$. However, $\frac{1}{2} \times \frac{1}{3}$ is different from $\frac{1}{3} \times \frac{1}{2}$ in reality despite of the same answer. $\frac{1}{2} \times \frac{1}{3}$ can be illustrated as cutting a cake into half first then cut the half into three equal parts but $\frac{1}{2} \times \frac{1}{3}$ is cutting a cake into three equal parts then cut one of the three into half. The procedures involved are different. Amy realized that repeated addition was a problematic conception in this case so she responded that no addition was involved. Thus, she first cut the bar to three equal parts then cut one of the three parts into half to explain $\frac{1}{2} \times \frac{1}{3}$ (see Figure 8). However, this was incorrect in terms of procedure. Amy noticed the change of meanings in the multiplication of fractions and did mention subconsciously the meaning of multiplication is "of". She interpreted the meaning of multiplication of fractions as taking out a fraction from an object and her sketching clearly indicated this operation. She did mention, "multiple of it" and we believed that she was referring to parts of an object.

Excerpt 5b: Beth's interpretation of $\frac{1}{2} \times \frac{1}{3}$

R: What is $\frac{1}{2} \times \frac{1}{3}$ ?

B: One third divided by two so it is one over six.

$\mathrm{R}$ : What is the meaning of multiplication in this case?

B: Divide!

We all know that $\frac{1}{2} \times \frac{1}{3}=\frac{1}{3} \div 2$ thus Beth interpreted the meaning of multiplication of $\frac{1}{2} \times \frac{1}{3}$ as division. In fact, her interpretation was based on the operation performed symbolically rather contextualisation of the expression. She didn't grasp the new mathematical meaning of multiplication in this new context even though she realised that repeated addition was a problematic conception in the multiplication of fractions.

\section{Extending the multiplication of fractions for the case of probability}

We explored further the conceptions of Amy and Beth on the multiplication of fractions for the case of probability.

Excerpt 6a: Amy's interpretation of $P(A$ and $B)=P(A) \times P(B)$

R: How would you explain the formulae $P(A$ and $B)=P(A) \times P(B)$ to your pupils?

A: Tossing a tail first means I partition my chance into two. Then tossing a head after the tail means I have to partition the chance into two again. Now I left one over four of chance.

$\mathrm{R}$ : What is the meaning of multiplication in the first formula?

A: Partition

To find the probability of event $\mathrm{A}$ and event $\mathrm{B}$ occurring together, we multiply the probability of event $\mathrm{A}$ and event $\mathrm{B}$ as shown in the formula $P(A$ and $B)=P(A) \times P(B)$. Amy made sense of the meaning of multiplication in this formula as partition. Her interpretation was based on the example of tossing a tail at first then followed by a head for a second toss. Her explanation was consistent with her interpretation for the multiplication of fractions in an earlier instance. 
Excerpt 6b: Beth's interpretation of $P(A$ and $B)=P(A) \times P(B)$

$\mathrm{R}$ : What is the meaning of multiplication in this formula?

B: Erm... No meaning here.

R: Can you explain further?

B: Haha... Couldn't be, right....but I can't see repetition and I also cannot see divide. Maybe is "and".

R: Why "and"?

B: Because of the "and" in this formula. But I wonder how can "and" become multiply? "and" is addition isn't it? The formulae have been used long ago, shouldn't wrong.

R: So what is the meaning of multiplication here?

B: Erm...I don't know. Maybe "and" but I'm not sure.

When Beth was asked to make sense of the formula $P(A$ and $B)=P(A) \times P(B)$, initially she couldn't give a meaning for the multiplication symbol involved. Then she speculated the meaning of the multiplication symbol as "and". She wasn't confident with meaning of multiplication as "and" at that moment because it conflicted with her existing knowledge on multiplication. For Beth, repeated addition was a problematic conception in this context because this meaning was not valid in this situation.

Most students have real life experiences related to addition. As a result, students are often being taught to recognise the word "and" in mathematics word problems and associate it to the operation of addition in symbolism. As an illustration, there are two red apples and three green apples in a bowl. How many apples are there in the bowl? With the word 'and', students may sense that the mathematical operation involved should be addition. Hence, students may build a conception that the word 'and' is associated to the operation of addition. Similarly, Beth also had this conception. We call this as a problematic convention in the context of probability. In this respect, a conventional way of saying, teaching, writing and drawing of a particular concept that does not support the sense making of a new context is called as a problematic convention. When Beth was asked to make sense of the formula $P(A$ and $B)=P(A) \times P(B)$, she realised the problematic convention in this formula (see Excerpt $6 \mathrm{~b}$ ). At first she interpreted the meaning of multiplication in this formula as the notion 'and'. But when being asked further, she wondered how the word 'and' could carry the meaning of multiplication in the formula. For Beth, 'and' was supposed to associate with the operation of addition. In fact, the meaning of multiplication in the formula $P(A$ and $B)=P(A) \times P(B)$ is the notion 'of' because the probability of any event must be less than or equal to 1 thus this indicates that we are dealing with fractions in the context of probability.

\section{DISCUSSION AND CONCLUSION}

This article reported how two mathematics teachers coped with the changes of meanings in multiplication due to the changes of contexts. As shown in our analysis, initially both Amy and Beth interpreted the meaning of multiplication as repeated addition. However, when the numbers involved in the multiplication have changed to another number system then the interpretation of multiplication may need to be changed according to the new context. It is evident that the idea of repeated addition may become a problematic conception as an individual moves from one number system to another number system such as negative integers and fractions. However, both of them perceive repeated addition as a supportive conception and they are constantly trying to build their understanding based on the idea of repeated addition in new contexts.

In this respect, Amy and Beth develop their own ways to remove the problematic aspect of the perceived supportive conception. Amy makes use of the commutative law of multiplication so as to remove the problematic aspect of her perceived supportive conception. On the other hand, Beth transfers the negative sign to the multiplicand in order to remove the perceived problematic aspect. When dealing with fractions, Beth interpreted the meaning of multiplication as division by focusing on the performed operation of symbolism. Amy realized the change of meanings in multiplication when both the multiplicand and multiplier were fractions. All these highlight the complexity in making sense of multiplication over the longer term. Amy is more sensitive to the changes of meanings of multiplication in comparison to Beth. Based on the collected data in this study, it seems like the teachers' different educational background make a difference in making sense of multiplication. Bear in mind that no generalization can be made based on these two cases only. Superficially, Amy who has a better and higher academic achievement is able to sense and cope with the changes of mathematical meanings better.

This study has enlightened us on how humans make sense of multiplication in particular how two teachers coped with the changes of meanings in multiplication. Both teachers knew how to compute the answers for the given expressions but the issues were: 1) Were they aware of the changes of meanings? 2) When did the meaning change? 3) How did they make sense of these changes? 4) Have they focused on the appropriate aspects in making sense of these changes? All these issues are important for teachers so that they can make sense of multiplication 
over the longer term which in turn can guide their students in making sense of multiplication. When a new learning experience from a new context fits nicely into a preconception that arises from an old context then the whole sense making process will be smooth and supportive. However when an existing conception conflicts with a new learning experience then the sense making process can be very problematic. Piaget (1952) used the term assimilation and accommodation to express how humans cope with our knowledge structure. In this respect, supportive conceptions resonate with the notion of assimilation where an individual doesn't need to reconstruct his/her knowledge structure. On the other hand, problematic conceptions resonate with the notion of accommodation where learners need to reconstruct their knowledge structure to accommodate the new learning experience in a new context. However, the framework used in this paper can offer more by considering the supportive aspects and problematic aspects of a particular conception. It is not just about assimilation or accommodation because some superficially supportive conceptions may have problematic aspect(s). On the other hand, some problematic conceptions may consist of supportive aspect(s). Depending on what learners focus at a particular time, different learners may have different sets of supportive conceptions and problematic conceptions. The framework of supportive and problematic conceptions is a potentially useful framework to illustrate how humans make sense of multiplication across different contexts. We believe that this framework is applicable to diverse topics in mathematics.

\section{REFERENCES}

Barmby, P., Harries, T., Higgins, S., \& Suggate, J. (2009). The array representation and primary students' understanding and reasoning in multiplication. Educational Studies in Mathematics, 70(3), $217-241$. https://doi.org/10.1007/s10649-008-9145-1

Bromley, D. B. (1986). The Case-study Method in Psychology and Related Disciplines. Chicheter: John Wiley \& Sons.

Bromley, D. B. (1990). Academic contributions to psychological counselling. 1. A philosophy of science for the study of individual cases. Counselling Psychology Quarterly, 3(3), 299-308. https:/ / doi.org/10.1080/09515079008254261

Chin, K. E. (2013). Making sense of mathematics: supportive and problematic conceptions with special reference to trigonometry (Unpublished doctoral thesis). University of Warwick, England. Retrieved from http:/ / wrap.warwick.ac.uk/58403/

Chin, K. E. (2014). Supportive and problematic aspects in mathematical thinking over the longer term. In S. Oesterle, C. Nicol, P. Liljedahl, \& D. Allan (Eds.), Proceedings of the 38th Conference of the International Group for the Psychology of Mathematics Education and the 36th Conference of the North American Chapter of the Psychology of Mathematics Education, 6, 41. Vancouver, Canada: PME.

Chin, K. E., \& Jiew, F. F. (in press). Knowing and grasping of two university students: The case of complex numbers. The Mathematics Enthusiast.

Chin, K. E., \& Tall, D. O. (2012). Making sense of mathematics through perception, operation and reason: The case of trigonometric functions. In Tai-Yih Tso (Eds.), Proceedings of the 36th Conference of the International Group for the Psychology of Mathematics Education, 4, 264. Taipei, Taiwan: PME.

Clark, F. B., \& Kamii, C. (1996). Identification of multiplicative thinking in children in grades 1-5. Journal for Research in Mathematics Education, 27, 41-51. https://doi.org/10.2307/749196

Devlin, K. (2007, September). What is conceptual understanding? [Online forum]. Retrieved from Mathematical Association of America website: http://www.maa.org/external_archive/devlin/devlin_09_07.html

Fischbein, E., Deri, M., Nello, M. S., \& Marino, M. S. (1985). The role of implicit models in solving verbal problems in multiplication and division. Journal for Research in Mathematics Education, 16(1), 3-17. https:/ / doi.org/10.2307/748969

Forgasz, H. J. (2006). Australian year 12 mathematics enrolments: Patterns and trends - past and present. Retrieved from Australian Mathematical Science Institute website: https://amsi.org.au/wpcontent/uploads/2015/01/Forgasz_2006_Y12_Mathematics_Enrolments.pdf

Greer, B. (1992). Multiplication and division as models of situations. In D. Grouws (Ed.), Handbook of research on mathematics teaching and learning (pp. 276-295). New York: Macmillan.

Izsák, A. (2004). Teaching and learning two-digit multiplication: Coordinating analyses of classroom practices and individual student learning. Mathematical Thinking and Learning, 6(1), 37-79. https://doi.org/10.1207/s15327833mt10601_3

Izsák, A. (2005). You have to count the squares: Applying knowledge in pieces to learning rectangular area. Journal of the Learning Sciences, 14(3), 361-403. https:/ / doi.org/10.1207/s15327809jls1403_2

Jiew, F. F., \& Chin, K. E. (in press). Supportive and problematic conceptions in making sense of multiplication: A case study. The Mathematics Enthusiast. 
Kaput, J. (1985). Multiplicative word problems and intensive quantities: An integrated software response (Technical Report). Cambridge, MA: Educational Technology Center.

Kilhamn, C. (2011). Making sense of negative numbers (Doctoral thesis). University of Gothenburg, Sweden. Retrieved from https://gupea.ub.gu.se/bitstream/2077/24151/1/gupea_2077_24151_1.pdf

Kouba, V. L. (1989). Children's solution strategies for equivalent set multiplication and division word problems. Journal for Research in Mathematics Education, 20, 147-158. https:/ / doi.org/10.2307/749279

Lampert, M. (1986a). Knowing, doing, and teaching multiplication. Cognition and Instruction, 3, 305-342. https://doi.org/10.1207/s1532690xci0304_1

Larsson, K., Pettersson, K., \& Andrews, P. (2017). Students' conceptualisations of multiplication as repeated addition or equal groups in relation to multi-digit and decimal numbers. The Journal of Mathematical Behavior, 48, 1-13. https:/ / doi.org/10.1016/j.jmathb.2017.07.003

Lima, R. N., \& Tall, D. (2008). Procedural embodiment and magic in linear equations. Educational Studies in Mathematics, 67(1), 3-18. https:/ / doi.org/10.1007/s10649-007-9086-0

Lo, J.-J., Grant, T. J., \& Flowers, J. (2008). Challenges in deepening prospective teachers' understanding of multiplication through justification. Journal of Mathematics Teacher Education, 11(1), 5-22. https:/ / doi.org/10.1007/s10857-007-9056-6

Mack, N. K. (2001). Building on informal knowledge through instruction in a complex content domain: Partitioning, units, and understanding multiplication of fractions. Journal for Research in Mathematics Education, 32(3), 267295. https:// doi.org/10.2307/749828

National Council of Teachers of Mathematics. (2009). Focus in High School Mathematics: Reasoning and Sense Making. Reston, VA: NCTM.

Nicholas, J., Poladin, L., Mack, J. \& Wilson, R. (2015). Mathematics preparation for university: Entry, pathways and impact on performance in first-year science and mathematics subjects. International Journal of Innovation in Science and Mathematics Education, 23(1), 37-51. Retrieved from https:/ / openjournals.library.sydney.edu.au/index.php/CAL/article/view/8488

O’Brien, T. C., \& Casey, S. A. (1983a). Children learning multiplication: Part I. School Science and Mathematics, 83(1), 246-251. https:/ / doi.org/10.1111/j.1949-8594.1983.tb15518.x

Piaget, J. (1952). The origins of intelligence in children (Cook, M. Trans.). New York, NY: International Universities Press, Inc. https:/ / doi.org/10.1037/11494-000

Seah, T. K. R. (2004). An investigation of the depth and breath of students' knowledge of multiplication as a basis for the development of multiplication thinking (Unpublished master's thesis). Griffin University.

Sfard, A. (1991). On the dual nature of mathematical conceptions: Reflections on processes and objects as different sides of the same coin. Educational Studies in Mathematics, 22(1), 1-36. https:/ / doi.org/10.1007/BF00302715

Siemon, D. (2004). Partitioning - The Missing Link in Building Fraction Knowledge and Confidence. Retrieved from http:/ / www.aamt.edu.au/members/vc2004/vc-siemon.pdf

Siemon, D., Beswick, K., Brady, K., Clark, J., Faragher, R., \& Warren, E. (2015). Teaching mathematics: foundations to middle years. South Melbourne, Vic: Oxford University Press.

Siemon, D., Breed, M., \& Virgona, J. (2005). From additive to multiplicative thinking: The big challenge of the middle years. In J. Mousley, L. Bragg, \& C. Campbell (Eds.), Mathematics: Celebrating achievement. Proceedings of the 42nd conference of the Mathematical Association of Victoria (pp. 278-286). Brunswick: MAV.

Simon, M. A., \& Blume, G. W. (1994). Building and understanding multiplicative relationships: A study of prospective elementary teachers. Journal for Research in Mathematics Education, 25(5), 472-494. https:// doi.org/10.2307/749486

Smith, A. (2018, October 15). Premier's push to have 100 per cent of students studying HSC maths. The Sydney Morning Herald. Retrieved from https:/ / www.smh.com.au/politics/nsw/premier-s-push-to-have-100-percent-of-students-studying-hsc-maths-20181014-p5091n.html?fbclid=IwAR1nHz1a7p-6jZW215WqtPbyBKGOr6PX1gf7xYWQskVAsueH0Zh5MWZGlQ

Smith, S. Z., \& Smith, M. E. (2006). Assessing elementary understanding of multiplication concepts. School Science and Mathematics, 106(3), 140-149. https:/ / doi.org/10.1111/j.1949-8594.2006.tb18171.x

Sudarshan, A., \& Aye, K.M. (2008). Teacher practices in mathematics classroom with at risk students. Paper presented at the Annual Meeting of the Australian Association for Research in Education, Brisbane.

Tall, D. O. (2013). How humans learn to think mathematically. New York, NY: Cambridge University Press. https:/ / doi.org/10.1017/CBO9781139565202 
Tall, D. O., \& Vinner, S. (1981). Concept image and concept definition in mathematics, with particular reference to limits and continuity. Educational Studies in Mathematics, 12, 151-169. https:/ / doi.org/10.1007/BF00305619

Thanheiser, E. (2010). Investigating further preservice teachers' conceptions of multidigit whole numbers: Refining a framework. Educational Studies in Mathematics, 75(3), 241-251. https:/ / doi.org/10.1007/s10649-010-9252-7

Webel, C., \& DeLeeuw, W. W. (2015). Meaning for fraction multiplication: Thematic analysis of mathematical task in three fifth grade classes. The Journal of Mathematical Behavior, 41, 123-140. https:/ / doi.org/10.1016/j.jmathb.2015.12.003

Whitacre, I., \& Nickerson, S. D. (2016). Investigating the improvement of prospective elementary teachers' number sense in reasoning about fraction magnitude. Journal of Mathematics Teacher Education, 19(1), 57-77. https:/ / doi.org/10.1007/s10857-014-9295-2

Wilson, R. \& Mack, J. (2014). Declines in high school mathematics and science participation: Evidence of students' and future teachers' disengagement with maths. International Journal of Innovation in Science and Mathematics Education, 22(7), 35-48. Retrieved from https://openjournals.library.sydney.edu.au/index.php/CAL/ article/view/7625

Young-Loveridge, J. (2005). Fostering multiplication using array-based materials. Journal of Australian Mathematics Teacher, 61(3), 34-40. Retrieved from https:/ / files.eric.ed.gov/fulltext/EJ743571.pdf

\section{http://www.ejmste.com}

